\title{
Segmented Phase of Ultraviolet (UV) Curable Thermoset Polyurethanes-Graphite (TPU-G) Composites
}

\author{
Anika Zafiah M. Rus, Nur Munirah Abdullah, M. F. L. Abdullah
}

\begin{abstract}
Segmented thermoset polymeric materials properties mainly classified through its carbonyl hydrogen bonding. The addition of graphite particle loading in polymeric materials tailored the functional characteristic of the composites. Therefore, the carbonyl hydrogen bonding in the hard segments of the synthesized segmented ultraviolet (UV) curable thermoset polyurethanes-graphite $(T P U-G)$ composites was identified. This composites based green polymer incorporated with varying graphite particles loading were prepared through slip casting method which cure upon UV light. These result in an enhancement of the carbonyl hydrogen bonding which tribute to degree of phase separation (DPS \%) in the TPU-G composites ranged from 10-20\%, as compared to that in the pure TPU. In addition, the spectroscopy detects the formation of carbonyl hydrogen groups within the TPU-G composites although they are prone to chain scission and undergo photo oxidation subjected to ultraviolet $(U V)$ curing. Upon UV curing, higher graphite weight loading (TPU-G $G_{20}$, $T P U-G_{25}$ and TPU-G $G_{30}$ composites), shows higher and stable DPS\% value, attribute to soft segment- soft segment and hard segment- hard segment establishment. Therefore, the graphite particles dominantly absorb the incident radiation instead of thermoset polyurethane without changing its based.
\end{abstract}

Index Terms: Thermoset polyurethane, graphite, segmented phase, ultraviolet curing, carbonyl hydrogen index.

\section{INTRODUCTION}

One of the most important polymer classes involves polyurethanes (Pus). On their main chain, these polymers have repeated groups that exist in the form -NHCOO-. Also, the polymers are renowned for their exceptional versatility relative to their application and property ranges. Hence, they are used in both flexible and rigid foams, as well as elastomers, thermoplastic parts, adhesives, and coatings [1-6]. When typical PUs are used, their preparation involves polyols reactions. The latter exist in the form of multi-isocyanate, which tends to be derived from petroleum.

Revised Manuscript Received on July 22, 2019

Anika Zafiah M. Rus, Sustainable Polymer Engineering, Advanced Manufacturing and Materials Center (SPEN-AMMC), Faculty of Mechanical and Manufacturing, Universiti Tun Hussein Onn Malaysia, 86400 Parit Raja, Batu Pahat, Johor, Malaysia.

Nur Munirah Abdullah, Sustainable Polymer Engineering, Advanced Manufacturing and Materials Center (SPEN-AMMC), Faculty of Mechanical and Manufacturing, Universiti Tun Hussein Onn Malaysia, 86400 Parit Raja, Batu Pahat, Johor, Malaysia.

M. F. L. Abdullah, Department of Communication Engineering, Faculty of Electrical and Electronic Engineering, Universiti Tun Hussein Onn Malaysia, 86400 Parit Raja, Batu Pahat, Johor, Malaysia.
Indeed, hard segments (HSs) and soft segments (SSs) characterize the multi-isocyanate.

Another notable aspect is that the mixing of HS and SS is energetically favorable. To ensure that elastomers properties are achieved by polymeric materials, it is imperative to note that the SS needs to be a dominant constituent by mass. In this case, the phase structure ends up assuming the form of a discrete hard domain, whose dispersion occurs in the soft matrix [6]. Such a phase structure gives impact on mechanical properties [7], so does the structural parameter, and therefore, is the degree of phase separation (DPS \%). Congruently, PUs phase separation strongly depends on the hydrogen bond formation between the urethane linkages (urea, amide and etc.) as well as on the manufacturing process, and reaction conditions [6]. The possible hydrogen bonds within Pus chain are shown in Fig. 1.

In previous research, thermoset polyurethane-graphite composites were proposed as 'green' conductive polymer composites as it form from virgin vegetable oil-based [8,9]. It is recorded that a strong interconnected particle between graphite particles and thermoset polyurethane matrix is evident to physical, mechanical [10,11], thermal [12] and electrical properties[13,14] of the TPU-G composites. Moreover, the enhancement of mechanical properties of ultraviolet (UV) curable TPU-G composites also have been published [15]. However, the positive responses of the carbonyl hydrogen bonding within the matrix with addition of graphite particles have not been disclosed elsewhere. Prior to this, the carbonyl hydrogen bonding-degree of phase separation (DPS \%) of segmented phase of thermoset polyurethane-graphite composites upon UV curing with different time irradiation $(250,500,750$ and 1000 hours $)$ are analysed.

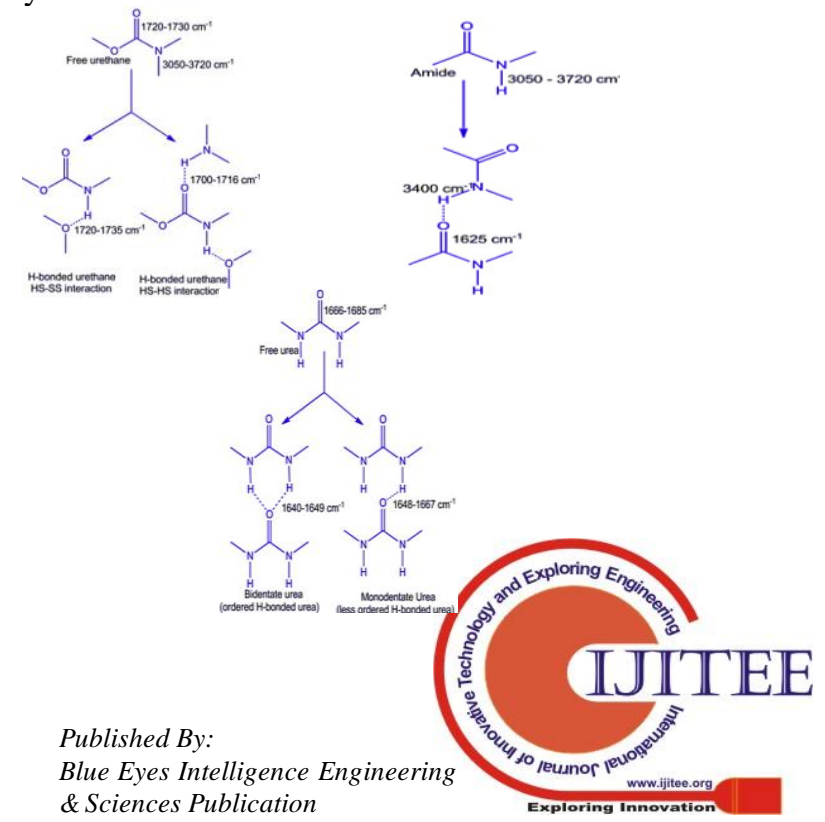


Fig.1: Possible hydrogen bonds in polyurethane chain [6]

Where the peak at $1701 \mathrm{~cm}-1$ is attributed to hydrogen bonded $-\mathrm{C}=\mathrm{O}$ and the peak at $1726 \mathrm{~cm}-1$ belongs to free $-\mathrm{C}=\mathrm{O}$.

\section{METHODOLOGY}

Several steps were employed towards the preparation of the polyurtane-graphite composites, which were free-standing. The initial step constituted graphite preparation whereby the graphite flake was mixed with sulfuric acid before being directed to a flask. This stage sought to provide room for the mixture to be sonicated at room temperature. The sonication period lasted about one hour. Upon sonication, there was a yellow solution, which suggested high-level graphite oxidation. With the graphite mixture precipitate obtained, its neutrality was achieved by collecting and washing it with water. The $\mathrm{pH}$ paper was used for confirming the neutrality of the precipitate. Later, it was dehydrated and an oven used to dry it [8]. The second step involved synthesizing the thermoset monomer. This procedure commenced with the preparation of an in-house catalyst, a process that involved the use of $1.26 \mathrm{~mL}$ hydrogen peroxide and $0.6 \mathrm{~mL}$ of distilled water; hence $30 \% \mathrm{w} / \mathrm{w}$. later, the heating of the solution was set at $50^{\circ} \mathrm{C}$ before stirring it for about half an hour. With the product placed at room temperature, aqueous orthophosphoric acid was introduced. Particularly, $1.2 \mathrm{~mL}$ of the acid were added, yielding $85 \% \mathrm{w} / \mathrm{w}$ and $90 \mathrm{mg}$. at the same temperature, there was the heating of $30 \mathrm{hm}$ of vegetable cooking oil before mixing with the initially prepared in-house catalyst. Also, $50 \mathrm{~mL}$ of water was added. It is also worth noting that given the mixture, there was a drop wise addition of hydrogen peroxide at $0 \% \mathrm{w} / \mathrm{w}$ and $18 \mathrm{~mL}$, as well as orthophosphoric acid at $85 \% \mathrm{w} / \mathrm{w}$ and $15 \mathrm{mg}$. The mixture would later be heated to $90^{\circ} \mathrm{C}$ before stirring it for about six hours. The process aided in achieving a double layer of mixture. The eventuality was that a renewable monomer was realized [13].

The third step involved thermoset polyurethane-graphite composite preparation. In this phase, Methylene Diphenyl Diisocyanate (MDI) was mixed with vegetable cooking oil (VCO). Also added to the mixture was the acid treated graphite at 30, 25, 20, 15, and 5\% w/w [12]. This mixture was then channeled into a square container before pre-curing it under standard room temperature. The later process lasted about an hour; leading to gelation formation. At different time exposures such as 1000, 750, 500 and 250 hours (see Figure 2), the Accelerate UV Weatherometer was used for further curing.

It is also worth indicating that in the investigation, an optical microscope aided in the observation of the composites' morphology. The specific device involved Nikon Eclipse LV/150NL. On the other hand, the Perkin Elmer Fourier Transform Infrared Spectroscopy (FTIR) aided in identifying the UV curable composites' infrared spectra; where the resolution was set at $4 \mathrm{~cm}^{-1}$ and the range set at $600-4000 \mathrm{~cm}^{-1}$.
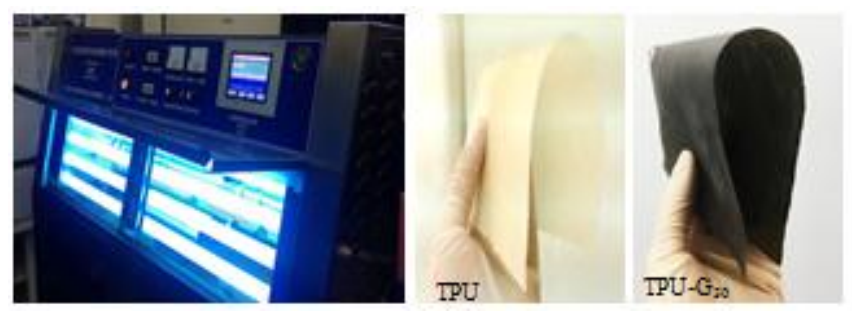

Fig. 2: UV curable thermoset polyurethane- graphite composites.

\section{RESULT AND DISCUSSIONS}

\section{A. Surface morphology}

At 100x magnification, the images obtained by the optical microscope (OM) depicted the thermoset polyurethane-graphite's clear surface morphology (see Figure 3). The yellowish and clean surface depicts pure thermoset polyurethane. When the content of graphite was increased from 5 to $30 \% \mathrm{w} / \mathrm{w}$, the filler experienced a flaky structure, causing connections and overlaps as the filler concentration increased. With the renewable polymer turning yellowish due to increasing graphite concentration, a darker color was later observed as the experiment progressed. The resultant inference is that in a polymer matrix, graphite addition causes a "visual" or "mirror-like" effect when observed from a cross-sectional perspective. This outcome is attribute to the increase in TPU-G composite surface area. Also, graphite flake stacks account for this outcome.

\section{Functionality of thermoset polyurethane-graphite composites}

Given the modified TPU-G, the majority of apparent bands that occur are similar to those experienced in the pure TPU. Thus, it becomes inferable that the chemical additives and groups' characteristics found in the selected thermoset polyurethane-graphite composites system are similar to the pure versions (see Figure 4). 


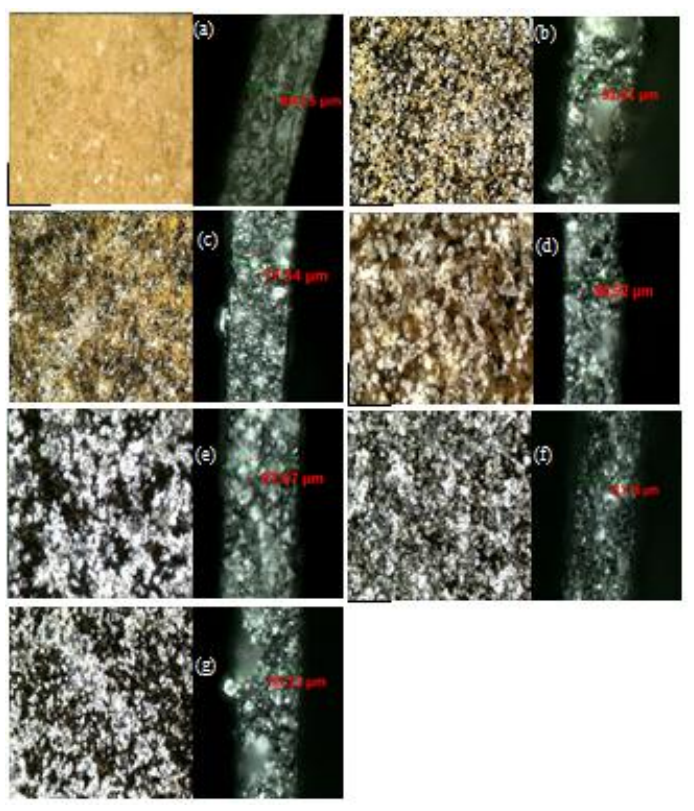

Fig. 3: Optical microscope images 100x magnification thermoset polyurethane- graphite composites (a) TPU, (b) TPU-G 5 , (c) TPU-G ${ }_{10}$, (d) TPU-G 15 , (e) TPU-G T $_{20}$, (f) TPU-G $\mathrm{G}_{25}$ and (g) TPU-G $\mathrm{G}_{30}$, with its cross-sectional view respectively.

At $2275 \mathrm{~cm}^{-1}$, the isocyanate band was lacking in the composites. The eventuality is that from MDI, the NCO groups had been bonded in the entirety. The outcome was urethane groups that constituted C-N $\left(1240 \mathrm{~cm}^{-1}\right)$ signals characterized by components such as C-O-C (1140-1180 $\left.\mathrm{cm}^{-1}\right), \mathrm{C}=\mathrm{O}\left(1730 \mathrm{~cm}^{-1}\right.$, and $\mathrm{N}-\mathrm{H}\left(3340 \mathrm{~cm}^{-1}\right.$. It was also at the strong peaks that ethers and esters formed. These peaks were between 1100 and $1200 \mathrm{~cm}^{-1}$. On the one hand, the ether group was associated with the side chain's vicinity. On the other hand, the urethane and fatty acid chains were linked to the ester group formation and location [16]. Particularly, the methoxy group reflected the ether group and was realized when the stage for renewable monomer production was implemented. The step involved ring-opening and the use of methanol. It is also notable that the value $3200 \mathrm{~cm}^{-1}$ reflected another peak and it was at this point, which involved the hydroxyl group, that there was the presence of treated graphite, graphite oxide, and graphite hygroscopicity [17].

Figure 5 shows the results relative to the implementation of the phase separation stage. Indeed, the bounded hydrogen bonds and the hard segment bonds were shared. In the TPU-G composites, hydrogen bonding was observed within the major functional groups' IR spectra. The groups included $\mathrm{C}-\mathrm{O}-\mathrm{C}\left(1200-1000 \mathrm{~cm}^{-1)}, \mathrm{C}=\mathrm{O}\left(1800-1600 \mathrm{~cm}^{-1}\right)\right.$, and $\mathrm{N}-\mathrm{H}$ $\left(3500-3200 \mathrm{~cm}^{-1}\right)$. Relative to the selected functional groups, the lone-pair electron was supplied by $\mathrm{C}-\mathrm{O}-\mathrm{C}$ while the proton was supplied by N-H. The eventuality is that two sets of hydrogen bonds were achieved. These bonds included $\mathrm{N}-\mathrm{H} / \mathrm{O}=\mathrm{C}$ and $\mathrm{N}-\mathrm{H} / \mathrm{O}-\mathrm{C}$. Whereas the soft segments experienced a dominance of the free carbonyl groups, the hard segments experienced a dominance of the N-H/O-C hydrogen bond.

Indeed, the study established a correlation between relative intensity and the extent to which phase separation would be achieved in FTIR spectra's $\mathrm{C}=\mathrm{O}$. the following equation aids in calculating the phase separation level (DPS) [16, 18].

$$
\mathrm{DPS}=\mathrm{R} /(\mathrm{R}+1)
$$

From the equation above, carbonyl hydrogen bonding is represented by $\mathrm{R}$ (1). In relation to the previous scholarly studies, such as Vega-baudrit et al., the highest loss and storage module values could be achieved in the wake of the highest hard segment content, as well as the highest DPS ratio. Moderating factors include the modulus of the softening (associated with phase mixture) and increased temperature [19]. From the findings, there is an increase in the DPR and $R$ values relative to the increase in the relative weight of the composites' graphite particles. Hence, it becomes inferable that in the TPU, dominant interactions involve soft segment-soft segment, given the graphite particles. For hydrogen bonding, these interactions alter the association-dissociation bonding.

\section{B. Functionality of ultraviolet curable thermoset polyurethane-graphite composites}

The spectroscopy through FTIR of TPU in Fig. 7 (a) and TPU-G $\mathrm{G}_{30}$ in Fig. 7 (b) confirmed the fingerprint of both UV curable polymeric composites are identical, in which the composites did not exhibit appreciable changes upon UV irradiation, specifically for the range of 1700- 4000 $\mathrm{cm}^{-1}$ region. At the left side of the graph reveals a stretching of the N-H group, which strongly suggest the formation of polyuria. Moving further towards right on the graph, all typical absorbance peaks of thermoset polyurethane, such those at 2800-3100 $\mathrm{cm}^{-1}\left(\mathrm{CH}_{2}\right.$ and $\left.\mathrm{CH}_{3}\right), 1724 \mathrm{~cm}^{-1}(\mathrm{C}=\mathrm{O}), 1030-1230 \mathrm{~cm}^{-1}(\mathrm{C}-\mathrm{N})$, and $1110 \mathrm{~cm}^{-1}(\mathrm{C}-\mathrm{O}-\mathrm{C})$, indicate the existence of urethane in synthesized thermoset polyurethane- graphite composites. Moreover, the stretching vibration band around 2270 $\mathrm{cm}^{-1}$ was diminished due to the reaction of isocyanate group during polymerization which confirmed the completion of process under UV curing [20].

From Figure 8 (a), there is a plateau band in the thermoset polyurethane. This outcome is linked to the presence of the UV curing phase. Hence, polyurethane materials are seen to undergo cross-linking or scissions, especially at the soft segment. At a range of 0 to 250 hours, the results demonstrate that there is radical initiation in the composite matrix. Beyond 250 hours, cross-linking occurs. At much higher magnitudes of 700 and 500 hours, there is cross-linking and propagation, with the magnitude of beyond 1000 hour experiencing chain scissions; especially due to UV curing exposure that affects the soft segment. With an increase in graphite loading, it is noticed that the level beyond $1300 \mathrm{~cm}^{-1}-1100 \mathrm{~cm}^{-1}$ experiences smaller peak ratios (see Figure $8(\mathrm{~b}-)$ ). Hence, the composites in these conditions experience limited formation o esters. A potential explanation for this trend is that the incident radiation is absorbed by the graphite particles. As this process occurs in the graphite particles at the expense of the polyurethane, ester formation reduces significantly [21]. 


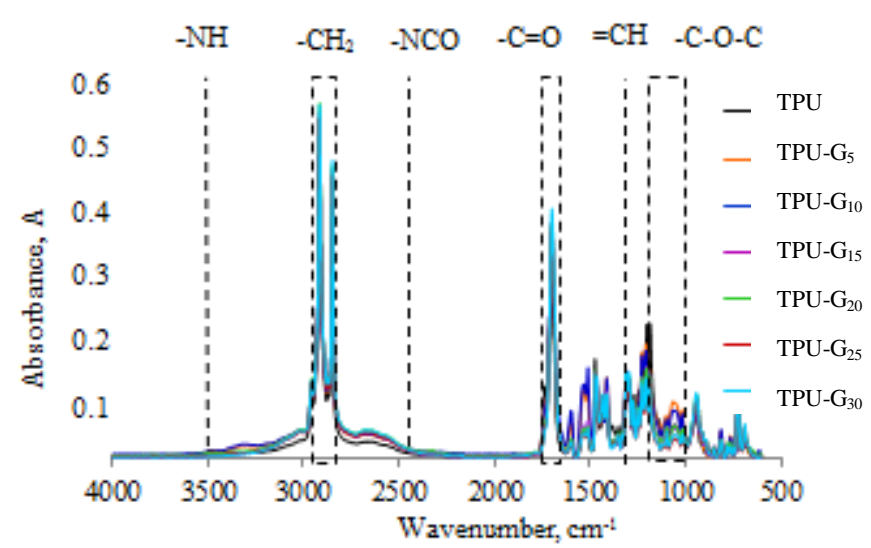

Fig. 4: FTIR spectra at region $4000-500 \mathrm{~cm}^{-1}$ of thermoset polyurethane-graphite composites.

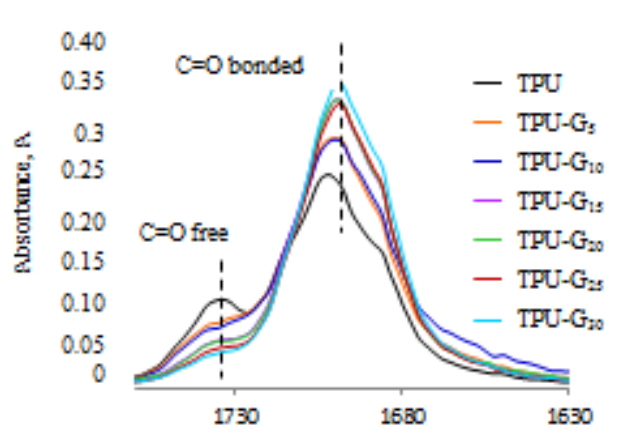

Fig. 5: FTIR spectra at region $2000-1000 \mathrm{~cm}^{-1}$ of thermoset polyurethane-graphite composites.

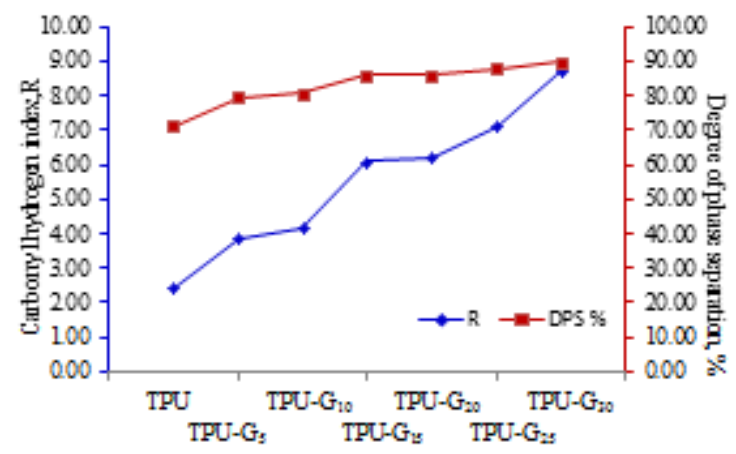

Fig.6: Calculated carbonyl hydrogen index, $\mathrm{R}$ and subsequent degree of phase separation (DPS \%) of thermoset polyurethane- graphite composites.

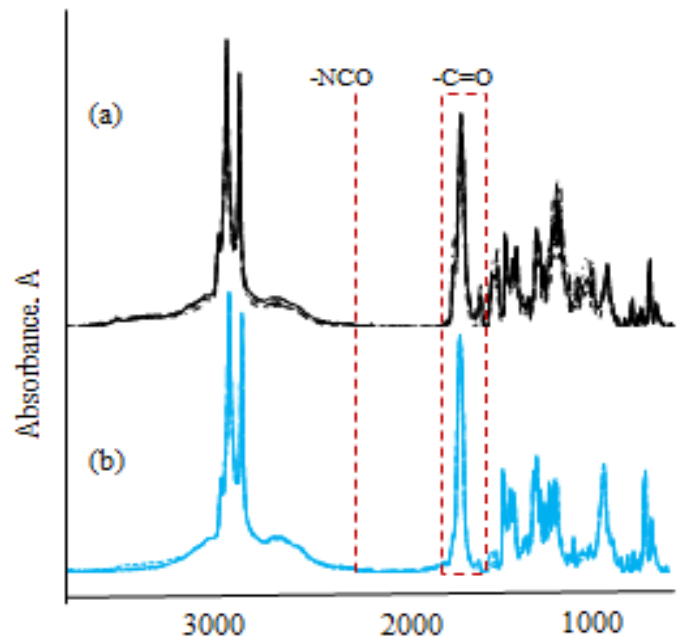

Fig. 7: FTIR spectra at region $4000-500 \mathrm{~cm}^{-1}$ of UV curable (a) TPU and (b) TPU-G $\mathrm{G}_{30}$ composites.
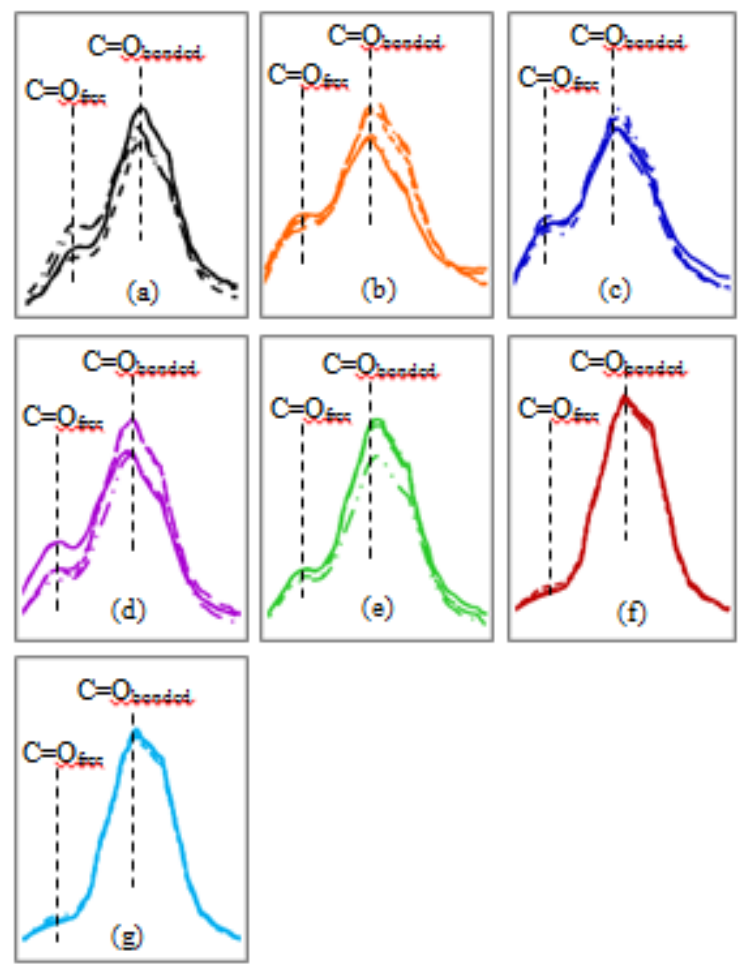

Fig. 8: FTIR spectra at region $2000-1000 \mathrm{~cm}^{-1}$ of UV curable (a) TPU, (b) TPU-G 5 , (c) TPU-G 10 , (d) TPU-G ${ }_{15}$, (e) TPU-G ${ }_{20}$, (f) TPU-G ${ }_{25}$, and TPU-G $\mathrm{G}_{30}$ composites.

As polymers are prone to chain scission and undergo photooxidation [22], the carbonyl hydrogen index and the degree of phase separation (DPS) values were obtained and plotted as shown in Fig. 9. As mentioned previously, the composites with the highest DPS ratio has the highest hard segment content [19]. The results clearly show plateau trends of that the carbonyl hydrogen index, $\mathrm{R}$ and degree of phase separation (DPS) of the composites. Nonetheless, both $\mathrm{R}$ and DPS values increase and stabilized the system as the weight percentage of graphite particles increased within the matrix which can be observable at $\mathrm{TPU}-\mathrm{G}_{20}, \mathrm{TPU}-\mathrm{G}_{25}$ and TPU-G $_{30}$ composites.

Consequence of this, higher 
values in the mechanical characteristics (storage and loss modules) were performed [15].

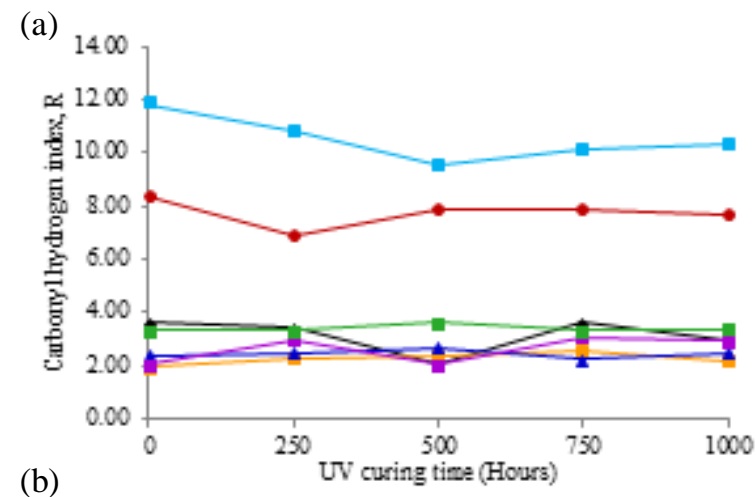

(b)

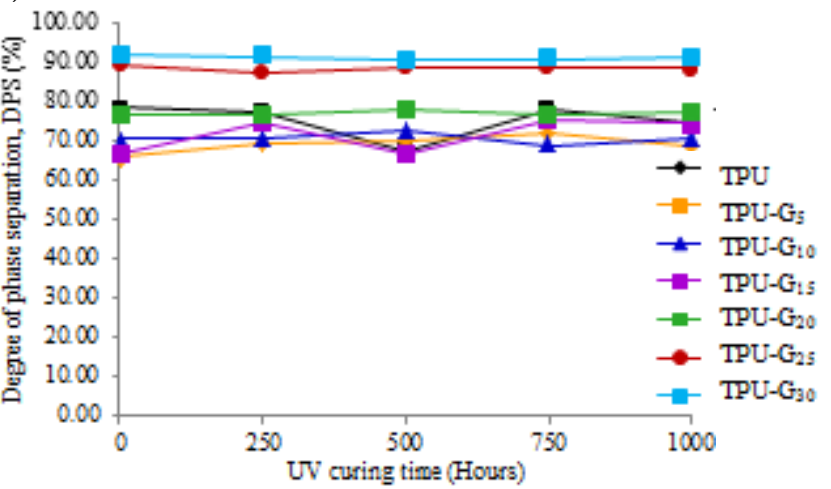

Fig. 9: (a) Carbonyl hydrogen index, $\mathrm{R}$ and (b) degree of phase separation, DPS (\%) of UV curable thermoset polyurethane-graphite composites.

\section{CONCLUSION}

This study infers that it is at the hard segment-hard segment and soft segment-soft segment platforms that the thermoset polyurethane based interactions for virgin vegetable oil occur. A factor that plays a moderating role in shaping these interactions is found to involve hydrogen bonding in relation to its association-dissociation equilibrium. As such, cross-link and polymerization are seen to occur simultaneously when FTIR spectroscopic UV curing is implemented.

\section{ACKNOWLEDGMENT}

Special gratitude goes to Fundamental Research Grant Scheme (Phase 1/2015) and its umbrella, the Ministry of Education Malaysia. Also, gratitude goes to research support groups involving the Universiti Tun Hussein Onn Malaysia (UTHM), MyBrain 15 (MyPhD), vot 1534, and Johor.

\section{REFERENCES}

[1] S. Li, C. Xu, W. Yang, Q. Tang, Thermoplastic Polyurethanes Stemming From Castor Oil : Green Synthesis And Their Application In Wood Bonding, Coatings. 7 (2017) 10.

[2] M. Kurańska, U. Cabulis, M. Auguścik, A. Prociak, J. Ryszkowska M. Kirpluks, Bio-Based Polyurethane-Polyisocyanurate Composites With An Intumescent Flame Retardant, Polym. Degrad. Stab. 127 (2015).

[3] H. Kim, Y. Miura, C.W. Macosko, Graphene/Polyurethane Nanocomposites For Improved Gas Barrier And Electrical Conductivity, Chem. Mater. 22 (2010) 3441-3450.

[4] E. Sancaktar, L. Bai, Electrically Conductive Epoxy Adhesives,
Polymers (Basel). 3 (2011) 427-466.

[5] T.F. Garrison, M.R. Kessler, R.C. Larock, Effects Of Unsaturation And Different Ring-Opening Methods On The Properties Of Vegetable Oil-Based Polyurethane Coatings, Polymer (Guildf). 55 (2014) 1004-1011. Doi:10.1016/J.Polymer.2014.01.014.

[6] C. Zhang, T.F. Garrison, S.A. Madbouly, M.R. Kessler, Progress In Polymer Science Recent Advances In Vegetable Oil-Based Polymers And Their Composites, Prog. Polym. Sci. 71 (2017) 91-143.

[7] Y. Zhang, W. Li, W. Wang, Rsc Advances Pu / Pmma Composites Synthesized By Reaction- Induced Phase Separation: A General Approach To Achieve A Shape Memory E Ff Ect $\dagger$, Rsc Adv. 7 (2017) 33701-33707.

[8] A.Z.M. Rus, N.M. Abdullah, M.F.L. Abdullah, M.I.F. Idris, Graphite/Bio-Based Epoxy Composites: Structural, Optical And Electrical Properties, Appl. Mech. Mater. 799-800 (2015) 153-157.

[9] A.Z.M. Rus, N.M. Abdullah, M.F.L. Abdullah, Interconnected Interface Enhanced Electrical Properties Of Graphite In Bio-Based Epoxy From Insulating To Conductor Composites, Indian J. Sci. Technol. 8 (2015) 8-12.

[10] A.Z.M. Rus, N.M. Abdullah, M.F.L. Abdullah, M.I.F. Idris, Graphite/ Bio-Based Epoxy Composites: The Mechanical Properties Interface, Appl. Mech. Mater. 799-800 (2015) $115-119$.

[11] N.M. Abdullah, M.F.L. Abdullah, Mechanical Reinforcement Of Conductive Graphite / Biopolymer Thin Film Composite, Arpn J. Eng. Appl. Sci. 10 (2015) 9772-9775.

[12] N.M. Abdullah, A.Z.M. Rus, M.F.L. Abdullah, Enhancement Of Graphite Functionality In Renewable Polymer Composite Properties, Int. J. Eng. Technol. 7 (2018) 215-220.

[13] N. Munirah, A. Zafiah, M. Rus, M.F.L. Abdullah, Synergistic Influence Of Graphite On Biopolymer Composites Properties, J. Teknol. 77 (2015) 11-19.

[14] N.M. Abdullah, M.S. Kamarudin, A.Z.M. Rus, M.F.L. Abdullah, Preparation Of Conductive Polymer Graphite ( Pg ) Composites, Iop Conf. Ser. Mater. Sci. Eng. 226 (2017).

[15] A.Z.M. Rus, N. Munirah Abdullah, M.F.L. Abdullah, Mechanical Behavior Of Ultra Violet (Uv) Curable Renewable Polymer/Graphite (Pg), Indian J. Sci. Technol. 9 (2016) 1-4.

[16] A. Syafiq, A. Hazmi, Understanding Intrinsic Plasticizer In Vegetable Oil-Based Polyurethane Elastomer As Enhanced Biomaterial, J. Therm. Anal. Calorim. (2017).

[17] K. Liu, B. He, L. Qian, J. Li, Conducting Graphite / Cellulose Composite Film As A Candidate For Chemical Vapor-Sensing Material, Bioresources. 9 (2014) 5279-5289.

[18] D. Cai, K. Yusoh, M. Song, The Mechanical Properties And Morphology Of A Graphite Oxide Nanoplatelet/Polyurethane Composite, Nanotechnology. 20 (2009) 85712.

[19] J. Vega-Baudrit, S.M. Carballo, L. De Adhesión, U. De Alicante, C. Rica, Thermoplastic Polyurethanes-Fumed Silica Composites: Influence Of Nco / Oh In The Study Of Thermal And Rheological Properties And Morphological Characteristics, Thermoplast. Compos. Mater. (2012) 12-24.

[20] T. Xu, Uv-Curable Hybrid Polyurethanes, Master Of Science, 2014.

[21] S.I. Khan, A Study On Graphene Based Nanocomposite Coatings Subjected To Uv Degradation, Master Of Engineering, 2007.

[22] N. Rajagopalan, A.S. Khanna, Effect Of Methyltrimethoxy Silane Modification On Yellowing Of Epoxy Coating On Uv ( B ) Exposure, J. Coatings. 2014 (2014) 7.

\section{AUTHORS PROFILE}

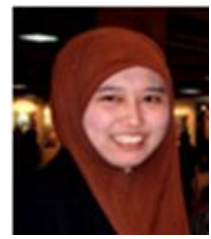

Anika Zafiah Mohd Rus is an Associate Professor in the Faculty of Mechanical and Manufacturing Engineering at the University of Tun Hussein Onn Malaysia (UTHM) She obtained her $\mathrm{PhD}$ in March 2007 from University of Warwick, United Kingdom in Polymer Chemistry and Engineering, BSc (Hons) in Mechanical Engineering (Manufacturing) in 1998 and MSc in Technical and Vocational in 1999 from University of Technology Malaysia (UTM), and her Diploma in Rubber and Plastics Technology from University of Technology MARA (UiTM) in 1993. She started her career as a lecturer at the Polytechnic Seberang Prai (PSP) in 1999 and was transferred to UTHM in 2000 (formerly known as PLSP). At the present she's a the Principle Researcher in the Advanced Manufacturing and Materials Center (AMMC), Faculty 
of Mechanical and Manufacturing Engineering. She had more than 10 years experience of teaching in higher education in Polytechnic and UTHM, which involved teaching in Electrical Technology, Engineering Sciences, Micro Teaching, Mechanical Engineering Skills, Materials Science, Engineering Materials Selection, Mechanical Engineering Design, Engineering Polymer and Advanced Polymer. zafiah@uthm.edu.my

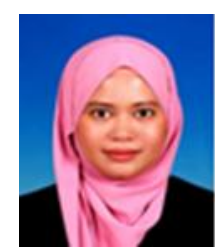

Nur Munirah Abdullah is currently a PhD student in Mechanical Engineering (Materials) from Universiti Tun Hussein Onn Malaysia (UTHM), Malaysia under the supervision of Associate Professor Dr. Anika Zafiah bt Mohd Rus and Associate Professor Dr. Muhammad Faiz Liew bin Abdullah. Her research purpose is centered on graphite/ renewable polymer conductive composites. Before that, she received M.A. (by Research) in Mechanical Engineering (Materials) from Universiti Tun Hussein Onn Malaysia (UTHM), Malaysia (2012) based on semiconductor materials with organic dye as sensitizer for dye-sensitized solar cell application whilst BSc. (Hons.) in Physics from Universiti Putra Malaysia (UPM), Malaysia (2009) focusing on dielectric properties of organic materials. nurmunirahabdullah87@gmail.com

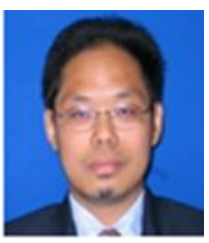

Mohammad Faiz Liew Abdullah is a Professor in the Faculty of Electrical and Electronic Engineering at the University of Tun Hussein Onn Malaysia (UTHM). He completed his $\mathrm{PhD}$ in August 2007 from University of Warwick, United Kingdom in Wireless Optical Communication Engineering. He received MEng by research in Optical Fiber Communication in 2000, $\mathrm{BSc}$ (Hons) in Electrical Engineering (Communication) in 1997 and Dip Education in 1999 from University of Technology Malaysia (UTM). His career path started as a lecturer at Polytechnic Seberang Prai (PSP) in 1999 and was transferred in 2000 to UTHM (formally known as PLSP). At the present he's an Associate Professor and the Deputy Dean (Research and Development), Faculty of Electrical \& Electronic Engineering, University Tun Hussein Onn Malaysia (UTHM). He had 15 years experience of teaching in higher education, which involved the subject Optical Fiber Communication, Advanced Optical Communication, Advanced Digital Signal Processing and etc. His research area of interest are wireless and optical communication, photonics and robotic in communication. 